\title{
O PÃO DO DIREITO À EDUCAÇÃO...
}

\author{
Agostinho dos Reis Monteiro*
}

\begin{abstract}
RE SU M 0: 0 direito à educação é um direito prioritário, mas não é direito a uma educação qualquer: é direito a uma educação com qualidade de "direito do homem". O neoliberalismo, potenciado pela globalização do mundo, é uma ideologia económica cuja lógica mercantilista é adversa à ética dos direitos do ser humano. A alternativa à globalização neoliberal está na realização do direito ao desenvolvimento como meta-direito, isto é, direito a um processo de desenvolvimento que respeite e favoreça a realização de todos os direitos. Respeitar, proteger e realizar todos os direitos do ser humano, e o direito à educação em particular, é a principal obrigação de um Estado de Direito. $O$ direito à educação é um paradigma novo para repensar a educação, transfigurar a escola e recriar a identidade dos profissionais da educação.
\end{abstract}

Palavras-chave: Direito à educação. Neoliberalismo. Direito ao desenvolvimento. O brigações do Estado. Novo paradigma.

\section{THE BREAD OF THE RIGHT TO EDUCATION...}

A BSTRA CT: This paper unfolds the following arguments: The right to education is a priority right. It is not a right to mediocre education, but to an education fashioned with the quality of a human right. D riven by the world globalization, neo-liberalism is an economical ideology whose business logic is adverse to the human rights Ethics. The alternative to the neo-liberal globalization is to achieve the right to develop as a "meta-right", that is, the right to a development process that respects and favors the fulfillment of all the rights. Respecting, protecting and fulfilling all the human rights and especially the right to education is the main obligation of the Rule of Law. The right to education is a new paradigm to rethink

* D outor pela Universidade de Paris VIII e pela Universidade Clássica de Lisboa na área do Direito Internacional da Educação e professor da Universidade Clássica de Lisboa. E -mail: a.reismonteiro@mail.telepac.pt 
education, transfigure school and re-create the identity of the education professionals.

Key words: Right to education. Neo-liberalism. Right to development. Obligations of the State. New paradigm.

\section{Introdução}

"D epois do pão, a educação é a primeira necessidade do povo" - disse Danton no tempo da Revolução Francesa, em 1793, na sessão da Convenção de 13 de Agosto. 0 direito à educação é uma qualidade de pão vital para uma vida humana. Esta é a ideia principal do texto que se segue, cujas linhas de argumentação são as seguintes:

- O direito à educação é um direito prioritário, mas não é direito a uma educação qualquer: é direito a uma educação com qualidade de "direito do homem".

- O neoliberalismo, potenciado pela globalização do mundo, é uma ideologia económica cuja lógica mercantilista é adversa à ética dos direitos do ser humano. A alternativa à globalização neoliberal está na realização do direito ao desenvolvimento como meta-direito, isto é, direito a um processo de desenvolvimento que respeite e favoreça a realização de todos os direitos.

- Respeitar, proteger e realizar todos os direitos do ser humano, e 0 direito à educação em particular, são as principais obrigações de um Estado de Direito.

- O direito à educação é um paradigma novo para repensar a educação, transfigurar a escola e recriar a identidade dos profissionais da educação.

\section{Significação do direito à educação}

\section{Sua prioridade}

O primado da educação é um princípio que se encontra nas fontes clássicas do pensamento pedagógico. É um primado antropológico, psicológico, moral, económico, político e jurídico:

- É um primado antropológico, porque um ser humano não nasce como a deusa grega Atena, saída acabada e adulta da 
cabeça de Zeus. É o único ser vivo que tem real necessidade e verdadeira capacidade de educação. A educação é um poder-ser, cuja ontologia é, citando E. Bloch, "uma ontologia do ainda-não-ser (...) uma verdadeira ontologia utópica" (apud Münster, 1997, p. 142, 144).

- É um primado psicológico, porque nós somos o que fazemos de nós, mas começamos por ser 0 que fizeram de nós. Somos principalmente o que a educação faz de nós, para nós, com ou sem nós, ou apesar de nós, eventualmente contra nós. Cada ser humano é esculpido pela sua educação, pelos ventos e marés da sua vida, mas também pela sua acção, pela sua capacidade de revolta. Como disse Sartre: "Temos razão para nos revoltar-nos" (apud Münster, 1997, p. 160).

- É um primado moral, porque o ser humano, "mais do que como animal racional, pode ser definido como animal moral", como afirma Aranguren (1996, p. 99). Na verdade, um ser humano vive (e pode morrer ou matar) pelos sentimentos e valores depositados no "poço do ser" da sua infância (Bachelard, 1960, p. 98).

- É um primado económico, como se reconhece cada vez mais. O livro de Bill $\mathrm{G}$ ates intitulado The road ahead (A rota do futuro), publicado em 1996, tem um capítulo intitulado "Educação: o melhor investimento" (C hapter 9 - Education: the best investment).

- É um primado político, porque só na polis (cidade) o ser humano pode realizar a sua natureza e felicidade. É o que A ristóteles quis dizer quando afirmou que "o homem é um animal político por natureza", no princípio de A s políticas (ou A política, na tradução mais corrente).

- Por todas estas razões, o primado da educação é também jurídico. É reconhecido logo no preâmbulo na D eclaração universal dos direitos do homem, como salientou um dos seus eminentes autores (René Cassin):

O Preâmbulo da Declaração menciona "as medidas progressivas de ordem nacional e internacional" só em segunda linha. [...] $\mathrm{Na}$ realidade, a acção da educação é anterior às "medidas" e condiciona 0 seu respeito. Mais ainda, é principalmente a ela que cabe preparar os espíritos para as grandes transformações nacionais ou internacionais, necessárias para que os direitos do homem sejam melhor respeitados, 
à medida que a comunidade internacional se consolida moralmente $\mathrm{e}$ juridicamente. (Apud Verdoodt, 1964, p. 325, 327)

Na verdade, o conhecimento e a capacidade de exercício dos direitos de cada um, assim como a consciência do dever de respeitar os direitos dos outros, dependem da realização do direito à educação. Esta prioridade tem sido recorrentemente assinalada, no plano doutrinário. Por exemplo, escreveu F. Przetacznik:

Entre os direitos individuais do homem, o direito à educação é o mais importante, com a única excepção do direito à vida, fonte de todos os direitos do homem. 0 direito à educação é uma condição prévia ao verdadeiro gozo de quase todos os direitos do homem por uma pessoa individual. Este direito é uma pedra angular de todos os direitos do homem, pois, se uma pessoa não é correctamente educada, ele ou ela é incapaz de gozar verdadeiramente os outros direitos do homem. Em consequência, a realização do direito à educação é a tarefa mais elevada que se impõe, tanto a cada indivíduo como ao Estado em que esse indivíduo vive. (Przetacznik, 1985, p. 257)

No texto de apresentação do Relatório sobre a situação das crianças no mundo - 1999, a Directora Geral do Fundo das Nações Unidas para a Infância (UNICEF) escreveu: "A Convenção sobre os direitos da criança é clara: a educação é o fundamento de uma vida livre e desenvolvida. Está no coração dos direitos de todas as crianças e dos deveres de todos os Estados". Noutro texto introdutório, o Secretário G eral das Nações Unidas (Kofi Annan) escreveu também: "A educação é um direito do ser humano, portador de uma imensa esperança de transformação. A liberdade, a democracia, o desenvolvimento humano durável, repousam neste direito". Como se lê na D eclaração da quarta Conferência internacional sobre a educação dos adultos (UNESCO, 1985) [Não consta na Biblio!?], "0 acto de aprender, que está no coração da actividade educativa, faz passar o ser humano do estado de objecto, à mercê do acontecimento, ao estatuto de sujeito criador da sua história".

Considerando este consensual primado, muitos autores tomam em conta que 0 direito à educação tem força de jus cogens ou "norma imperativa", no sentido da Convenção sobre 0 D ireito dos Tratados (Viena, 1999). É o caso de R. Badinter, que inclui o direito à instrução no "núcleo duro dos direitos do homem", como condição da liberdade de pensamento e de expressão: "Se olharmos para a história da humanidade, foi da liberdade de pensamento e da liberdade de expressão dos seres humanos que saíram os progressos da ciência, da condição humana e as grandes obras da nossa cultura" (Badinter, 1990, p. 186). Tam- 
bém Von Struve considerou o direito à vida, 0 direito à educação e 0 direito ao livre desenvolvimento das potencialidades naturais como "os três direitos eternos e inalienáveis do homem" (apud Perschel, 1984, p. 550). E Van Bueren observa que a Carta Internacional dos Direitos do Homem considera "o direito à educação tão fundamental que é inderrogável” (Van Bueren, 1995, p. 233). ${ }^{1}$

\section{Seu conteúdo}

Os "direitos do homem" são fundamentais e universais porque exprimem as aspirações mais inerentes à dignidade de todo o ser humano.

0 conteúdo jurídico de um direito é determinado pela identificação da sua titularidade, objecto e oponibilidade, importando saber também de que meios de proteç̧ão dispõe. Responde às interrogações seguintes: é direito de quem (sujeitos activos)? A quê? D evido por quem (sujeitos passivos)? E como pode ser reclamado, em caso de violação? A especificidade de cada direito reside principalmente no teor normativo do seu objecto, cujo respeito pode ser avaliado segundo três critérios: disponibilidade, acessibilidade e qualidade. A disponibilidade significa a existência dos recursos materiais, técnicos e pessoais exigíveis. A acessibilidade implica não-discriminação, não-dificuldade de acesso físico e económico, bem como o acesso à informação pertinente. A qualidade consiste na aceitabilidade ética, cultural e individual, assim como na competência profissional.

As fontes normativas superiores dos direitos do ser humano encontram-se no Direito Internacional dos Direitos do Homem, um ramo do Direito Internacional nascido da D eclaração universal dos direitos do homem e formado por mais de 60 tratados e muitos outros instrumentos jurídicos. As normas relativas ao direito à educação estão dispersas em mais de uma centena de instrumentos jurídicos em nível universal e regional, de natureza convencional e declaratória, de conteúdo geral, específico e categorial. Formam - com seus travaux préparatoires (trabalhos preparatórios), jurisprudência, doutrina, mecanismos de protecção e implicações político-pedagógicas - o Direito Internacional da Educação, cujas disposições principais são, hoje, as seguintes:

- Artigo 26 da Declaração universal dos direitos do homem (1948).

- Artigos 13 e 14 do Pacto internacional sobre os direitos económicos, sociais e culturais (1966). 
- Artigos 28 e 29 da Convenção sobre os direitos da criança (1989).

Na sua O bservação Geral 13 sobre o direito à educação (E/ C.12/ 1999/ 10, par. 5), ${ }^{2}$ o Comité dos Direitos Económicos, Sociais e Culturais considerou que "uma interpretação contemporânea" do Artigo 13.1 do Pacto (parágrafo relativo aos fins da educação) deve ter em conta também, além da Convenção sobre os direitos da criança, outros textos que "receberam um amplo apoio em todas as regiões do mundo", a saber:

- Artigo 1 da D eclaração mundial sobre a educação para todos: responder às necessidades educativas fundamentais (Jomtien, Tailândia, 1990).

- Parágrafo 33 da primeira parte e parágrafo 80 da segunda parte da D eclaração e Programa de A cção da Conferência mundial sobre os direitos do homem (Viena, Áustria, 1993).

- Parágrafo 2 do Plano de acção para a D écada das N ações U nidas para a educação no domínio dos direitos do homem (1995$2004)$.

0 direito à educação, pela sua natureza transversal (cros-sectoral nature), "é geralmente considerado pelos especialistas um dos direitos mais complexos", como observou M. Mehedi num estudo para a Subcomissão de Promoção e de Protecção dos Direitos do Homem (Nações Unidas), de que foi membro (E/ CN.4/ Sub.2/ 1999/ 10, par. 50). A sua complexidade começa na sua titularidade. $O$ direito à educação - escreveu A.-Ch. Kiss - "é um direito complexo", sobretudo quando se trata da criança, porque "as crianças são realmente os seus titulares e beneficiários, mas é o Estado que deve assegurar a sua realização e são os pais que escolhem as modalidades do seu exercício" (Kiss, 1975, p. 432). Isto é, a educação é objecto de várias pretensões de direito: dos pais, desde sempre, porque os filhos são seus; dos Estados, sobretudo desde 0 aparecimento do Estado-nação, porque os cidadãos são também seus e, em todo o caso, porque na educação está em jogo 0 Bem Comum; sem esquecer os interesses das religiões, ao longo dos tempos; e ainda - at last but not at all the least - o interesse dos próprios educandos, que começam por estar na mais absoluta dependência dos adultos. Esta concorrência de interesses é a questão mais sensível e decisiva do direito à educação. 0 Artigo 26 da D edaração universal dos direitos do homem deixou-a indecisa. A sua resolução coerente com a lógica dos "direitos do homem" teve de esperar pela C onvenção sobre os direitos da criança, quatro décadas depois: o princípio do primado do 
"interesse superior da criança" implica o primado do interesse superior do educando, eventualmente contra a família ou contra o Estado, que apenas são titulares funcionais dos direitos dos filhos e dos cidadãos, na medida em que são responsáveis pela sua realização. Nessa Convenção, o direito à educação alcançou a plenitude jurídica da sua individualização, entendida "como atribuição de direitos individuais, independentemente da pertença a uma colectividade ou a uma instituição determinada" (Supiot, 1990, p. 489). Esta evolução tem a significação de uma verdadeira "reconstrução do direito à educação", como escreveu Van Bueren (1995, p. 256).

Passemos à definição do conteúdo do direito à educação.

0 direito à educação é um direito de "toda a pessoa", sem discriminação alguma e sem limites de tempo ou espaços exclusivos para o seu exercício. É direito da criança e do adulto, da mulher e do homem, seja qual for a sua capacidade física e mental, a sua condição e situação. É direito dos brancos, dos pretos, dos mestiços e dos amarelos, dos pobres e dos ricos, dos emigrantes, dos refugiados, dos presos etc. É direito das populações indígenas e de todas as minorias. Mas há prioridades a considerar:

- A prioridade da criança, que é o ser-educando por excelência, dada a intensidade da sua educabilidade e a ressonância pessoal e social da educação da infância, principalmente da primeira infância.

- A prioridade das meninas, pelas discriminações de que continuam a ser vítimas e pela repercussão que a educação das mães tem nos filhos e na sociedade em geral.

- A prioridade das pessoas iletradas, diminuídas na sua capacidade de "ser gente", como gostava de dizer Paulo Freire.

0 direito à educação é direito ao que está prescrito nas normas internacionais como finalidade, conteúdos e níveis de educação. 0 Artigo 26 da D eclaração universal dos direitos do homem, retomado e desenvolvido pelas normas internacionais principais, consagra como fim primeiro do direito à educação "o pleno desenvolvimento da personalidade humana", um fim que resume todos os outros. O u seja, direito à educação é direito às aprendizagens indispensáveis ao desenvolvimento de todas as dimensões da personalidade humana, desde a sua dimensão física à sua dimensão estética, no interesse individual e social. É, portanto, direito à "visão alargada" da "educação fundamental" adoptada pela D eclaração mundial sobre a educação para todos: res- 
ponder às necessidades educativas fundamentais (Jomtien, Tailândia, 1990), e reafirmada pelo Q uadro de A cção de D acar - E ducação para todos: cumprir os nossos compromissos colectivos (D acar, Senegal, 2000).

O direito à educação obriga os pais, os Estados, a Comunidade Internacional e os próprios educandos. Os pais são naturalmente os primeiros responsáveis pelo direito à educação dos filhos, mas o Estado é o principal responsável pela satisfação do direito à educação, por duas grandes razões: porque as famílias, sobretudo as mais pobres, não têm os recursos necessários para criar todas as possibilidades de satisfação do direito à educação, e porque 0 Estado é o órgão do Bem Comum formulado nas normas fundamentais de cada comunidade nacional e da Comunidade Internacional, as mais importantes das quais são as que reconhecem os direitos do ser humano. Para os mais fortes, o Estado pode ser um obstáculo à sua liberdade, mas os mais fracos precisam dele porque não podem pagar o preço da liberdade. A metade das crianças do mundo cuja satisfação do direito à educação é prejudicada por obstáculos financeiros e as crianças de mais de 40 Estados onde a escola primária ainda não é obrigatória nem gratuita só podem ter esperança na responsabilidade do Estado. Voltaremos, mais adiante, às obrigações do Estado.

Também a Comunidade Internacional organizada tem uma responsabilidade concorrente, subsidiária e supletiva dos Estados, na protecção e promoção dos direitos do ser humano. No que respeita ao direito à educação, essa responsabilidade foi reafirmada pela Declaração de Jomtien, no primeiro parágrafo do seu Artigo 10: "Satisfazer as necessidades educativas fundamentais constitui uma responsabilidade comum e universal da humanidade, que exige a solidariedade internacional e relações económicas equitativas e justas, a fim de corrigir as disparidades económicas existentes" [em itálico no texto].

Enfim, o direito à educação é também um dever de cada ser humano para com a sua dignidade e perfectibilidade, assim como para com a(s) comunidade(s) a que pertence, na medida da sua capacidade de responsabilidade. A D eclaração americana dos direitos e deveres do homem (1948) afirma expressamente no seu Artigo XXX I: "Toda a pessoa tem o dever de adquirir, pelo menos, a instrução primária".

Quanto à protecção do direito à educação, o Direito interno é "o quadro jurídico da realização e do exercício dos direitos do homem e das liberdades fundamentais", devendo ser conforme ao Direito In- 
ternacional, como se lê no Artigo 3 da D eclaração sobre o direito e a responsabilidade dos indivíduos, grupos e órgãos da sociedade de promover e proteger os direitos do homem e as liberdades fundamentais universalmente reconhecidos, adoptada pela Assembleia Geral das Nações Unidas em 1998. A protecção internacional do direito à educação dispõe dos mecanismos comuns a outros direitos - em nível universal (no quadro das Nações Unidas) e regional (no quadro europeu, americano e africano) - e de alguns mecanismos particulares, no âmbito da Organização das Nações Unidas para a Educação, a Ciência e a Cultura (UNESCO). Mas é um último recurso, só admitido depois de esgotadas as possibilidades de justiciabilidade interna.

Ainda não há, no plano universal, uma verdadeira jurisprudência sobre o direito à educação. A penas há uma "quase-jurisprudência”, como é qualificada a prática do $\mathrm{G}$ eneral $\mathrm{C}$ omment (O bservação Geral) adoptada pelos Comités das Nações Unidas. Interessam ao direito à educação sobretudo as $\mathrm{O}$ bservações Gerais do Comité dos Direitos do Homem, mas principalmente do Comité dos Direitos Económicos, Sociais e Culturais e do Comité dos Direitos da Criança. É no plano regional, no quadro do Conselho da Europa, que está mais desenvolvido um mecanismo de protecção dos direitos do homem e se encontra a mais importante jurisprudência internacional relativa ao direito à educação, produzida pelos órgãos da $\mathrm{C}$ onvenção europeia dos direitos do homem (a Comissão europeia dos Direitos do Homem e o Tribunal europeu dos Direitos do Homem, fundidos num tribunal permanente desde 1998). Por exemplo, o Tribunal europeu condenou sucessivamente a aplicação de castigos corporais nas escolas públicas, privadas e até no seio da família, no Reino Unido, que teve de alterar o seu Direito interno de modo que protegesse, no domínio da educação, os direitos garantidos pela Convenção europeia. Outro exemplo: num acórdão pronunciado em 1976 (relativo ao Processo Kjeldsen, Busk Madsen and Pedersen), o Tribunal Europeu decidiu que o governo da D inamarca tinha legitimidade para introduzir a educação sexual nas escolas públicas, mesmo contra a vontade de alguns pais. $\mathrm{O}$ alcance desta jurisprudência transcende amplamente 0 âmbito em que foi produzida.

No tempo da globalização neoliberal, de uma revolução tecnológica que faz do ser humano um apêndice da máquina e de cinismo da política internacional, o direito à educação e os "direitos do homem" em geral carecem, mais do que nunca, de um Estado forte e de uma Comunidade Internacional atenta e activa. 
O neoliberalismo está na ordem do dia, como sabemos. Significa o regresso aos princípios da economia liberal do século XVIII, cuja referência clássica é Adam Smith. Irrompeu nos anos Thatcher (1979-1990), no Reino Unido, e nos anos Reagan (1980-1988) nos EUA, na sequência da crise da dívida externa dos países em desenvolvimento que, de 1972 a 1981, multiplicou-se por dez, a uma velocidade muito superior à do crescimento do seu produto interno (ou nacional) bruto (PIB/ PNB). O "decálogo" neoliberal é o impropriamente chamado C onsensus de Washington, uma expressão utilizada em 1989 pelo economista John Williamson, que resumiu em dez recomendações o pensamento dominante nas "instituições de Bretton Woods" e no Departamento do Tesouro dos EuA.

As instituições de Bretton Woods são o Banco Mundial (вM) e 0 Fundo Monetário Internacional (FMI), criados por uma Conferência monetária e financeira das Nações Unidas, reunida em Bretton Woods, New Hampshire (EUA), em 1944. Têm sede em Washington. O Bм (formalmente BIRD: Banco Internacional para a Reconstrução e o D esenvolvimento) é a principal agência internacional em matéria de desenvolvimento e a maior fonte mundial de ajuda ao desenvolvimento, sendo o seu parecer decisivo junto de outras fontes de financiamento dos Estados. A missão do FMI é garantir a estabilidade do sistema financeiro internacional.

Em 1947, foi instituído o Acordo Geral sobre as Tarifas Aduaneiras e o Comércio (GATT) como fórum de negociação, regulação e supervisão do comércio internacional. 0 maior ciclo de negociações da história foi o U ruguay Round (Ciclo do Uruguai), que durou oito anos e conduziu ao Acordo Geral sobre o Comércio dos Serviços (GATS), assinado em Marrakesh (Marrocos), em abril de 1994. Na sequiência deste acordo, 0 GATT foi substituído por uma nova organização internacional, a O rganização Mundial do Comércio (o MC/ wTo), que nasceu formalmente a 1ํ de janeiro de 1995.

O neoliberalismo cavalgou a onda da globalização, que é, como se sabe, um processo de contracção do espaço e do tempo, de dissolução de fronteiras e de interconexão da vida das pessoas e dos povos. Não é um fenómeno novo, tem uma história secular, mas uma nova era começou nos anos de 1990, com a expansão da Internet. A nova era da globalização é um processo irreversível de refundação da civilização, mas é ambivalente. Até agora, tem sido um instrumento do império 
neoliberal, governado pelo poder económico (e militar) dos EUA, por meio do BM, do FMI, da oMC e das corporações multinacionais (MNCS: Multinational Corporations, que controlam o comércio mundial e gerem grande parte da riqueza do mundo). 0 BM e 0 FMI exercem, de facto, um grande poder sobre o destino dos povos, mas são instituições sem legitimidade democrática. Embora pertencendo ao sistema das Nações Unidas, têm funcionado à margem do seu Direito Internacional, sob a lei do mais rico e mais forte: um dólar, um voto (no Conselho Executivo do FMI, formado por 24 membros, o voto dos EUA tem um peso equivalente à soma dos pesos de Japão, Alemanha, França e Reino Unido). E a omc funciona também com regras injustas e permissivas da concorrência desleal dos países ricos, principalmente dos EUA: os mais poderosos impõem aos mais fracos regras que eles próprios não cumprem. Chomsky escreveu, a este propósito: "O s U.S. foram sempre pioneiros e bastião do proteccionismo, e é por isso que são um país rico, poderoso" (apud Fox, 2001, p. 79). Na realidade, segundo muitos economistas, historicamente, o proteccionismo económico favoreceu o pleno emprego, o crescimento económico e o comércio internacional. Não é a abertura que traz o crescimento económico, é o crescimento que permite às economias abrirem-se.

O neoliberalismo apresenta-se como ideologia económica do "mundo livre", vantajosa para todos e para a democracia, mas a sua causa não é a da liberdade, é a do lucro pelo lucro. É um fundamentalismo económico cujo dogma é a liberdade de circulação de mercadorias, serviços e capitais, e cujos mandamentos são a desregulação, a privatização de tudo quanto pode ser fonte de mais-valias e 0 desinvestimento público nos sectores "não-produtivos" ou de "rendimento diferido" (saúde, educação etc.). É uma ditadura macroeconómica que já pouco tem a ver com o espírito liberal de Adam Smith, um filósofo moral e economista progressista na sua época, como observa Chomsky. $\mathrm{O}$ seu mundo é um mercado sem fronteiras nem sentido do Bem Comum, por meio da submissão e do enfraquecimento dos Estados e da instrumentalização das pessoas, reduzidas à condição de mão-de-obra e de consumidores. Não cuida nas necessidades fundamentais da grande maioria da humanidade. Pelo contrário, a sua eficácia produtiva é de uma brutalidade destruidora dos seres humanos e da natureza. É verdade que o PNB/ PIB mundial se multiplicou por nove na segunda metade do século XX, mas nas duas últimas décadas o crescimento global diminuiu, a desigualdade e a pobreza extrema cresceram. Na América Latina e Caraíbas, por exemplo, em 
1980, 120 milhões de pessoas (41\% da população) viviam abaixo do limiar de pobreza. Em 1999, eram cerca de 220 milhões (45\%). Segundo números recentes, $43 \%$ dos 480 milhões de latino-americanos vivem abaixo do limiar de pobreza. ${ }^{3}$ A meio dos anos de 1990, a O rganização Internacional do Trabalho (отт) calculava que cerca de $30 \%$ da força laboral mundial estava no desemprego. Cerca de 1/ 5 da humanidade detém cerca de $4 / 5$ dos recursos. "O neoliberalismo é, na sua essência, um sistema concebido para servir os ricos" (Fox, 2001, p. 38-39).

As crises financeiras que abalaram o sistema financeiro mundial nos últimos anos da década de 1990 solaparam a ilusão neoliberal. Redescobre-se a importância da função do Estado e dos valores culturais e sociais. O próprio BM, que avalia em $70 \%$ a taxa de insucesso dos seus projectos, está a introduzir os "direitos humanos" no seu discurso, nos últimos anos (sob a presidência de James Wolfensohn). Numa publicação de 1998 (ano do quinquagésimo aniversário da D e claração universal dos direitos do homem), lê-se: "O Banco Mundial acredita que a criação de condições para a concretização dos direitos humanos é um objectivo central e irredutível do desenvolvimento. (...) O Banco contribui directamente para a realização de muitos direitos enunciados na Declaração Universal" (D evelopment and human rights: the role of the World Bank). Reflectindo uma nova visão do desenvolvimento, 0 BM adoptou um Quadro para o D esenvolvimento G lobal (CDF: C omprehensive D evelopment F ramework).

Mas voltemo-nos para o direito à educação, objecto deste texto.

O Acordo Geral sobre o Comércio dos Serviços (Gats) suscita três grandes questões, cuja gravidade está na origem da grande corrente de contestação da globalização em curso e principalmente das iniciativas do Fórum Social Mundial e do Fórum Mundial da Educação, em Porto Alegre. Essas questões podem ser resumidas nos subtítulos seguintes:

- D esenvolvimento e direitos humanos;

- Direitos humanos e obrigações dos Estados;

- O brigações dos Estados no domínio do direito à educação.

D esenvolvimento e direitos humanos

O quid da questão da globalização é o modelo de desenvolvimento de que ela é instrumento: um desenvolvimento fundado na ex- 
ploração do homem pelo homem ou no "direito do homem" ao desenvolvimento?

A té ao meio dos anos de 1960, desenvolvimento era sinónimo de crescimento económico, tendo como indicador principal o PIB/ PNB. Era uma concepção do desenvolvimento social redutora, instrumentalizadora da pessoa humana, socialmente injusta e ecologicamente insustentável. A crítica desta concepção economicista subiu de tom durante as comemorações do 20 o aniversário da D eclaração universal dos direitos do homem, em 1968, cujo ponto alto foi a Conferência internacional sobre os direitos do homem, em Teerão (Irão), de 22 de abril a 13 de maio. Foi neste contexto de emergência de uma nova visão do desenvolvimento, no quadro das Nações Unidas, que nasceu o Direito Internacional do D esenvolvimento. Começou por ser um direito da ajuda internacional, de natureza assistencial, que inspirou as duas primeiras Décadas das Nações Unidas para o D esenvolvimento, mas é, hoje, um ramo do Direito Internacional cujo objecto são as normas e obrigações decorrentes do "direito do homem" ao desenvolvimento.

0 direito ao desenvolvimento estava implícito na $\mathrm{D}$ eclaração universal dos direitos do homem, como é amplamente reconhecido, mas a expressão só aparece, pela primeira vez, no quadro das Nações Unidas, na Resolução 4 (XXXIII) de 21 de fevereiro de 1977 da Comissão dos Direitos do Homem. A 4 de dezembro de 1986, a Assembleia Geral das Nações Unidas adoptou uma D eclaração sobre o direito ao desenvolvimento. O seu Artigo 2.1 proclama: "O ser humano é 0 sujeito central do desenvolvimento e deve ser, pois, participante activo e beneficiário do direito ao desenvolvimento". A Conferência mundial sobre os direitos do homem (Viena, 1993), no seu documento final, reafirmou o direito ao desenvolvimento como "direito universal e inalienável" (ponto 10), reconhecendo: "A democracia, o desenvolvimento e 0 respeito dos direitos do homem e das liberdades fundamentais são interdependentes e reforçam-se mutuamente" (ponto 8).

Entretanto, o PNUD começou a publicar anualmente (a partir de 1990) um Relatório sobre o desenvolvimento humano. Para medir o desenvolvimento de um país de um modo menos grosseiro que o PIB/ PNB, adoptou como indicador um índice de desenvolvimento humano (IDH) composto "segundo três critérios essenciais ao desenvolvimento humano: longevidade, acesso ao saber e nível de vida", embora omisso quanto à sua repartição no interior de cada país (PNUD, 2001, p. 14, 15). 
A 8 de setembro de 2000, os chefes de Estado e de governo dos Estados-membros da O rganização das Nações Unidas, reunidos em Nova York, proclamaram a D edaração do Milénio. É uma histórica reafirmação dos "propósitos e princípios da Carta das Nações Unidas, que mostraram ser intemporais e universais" (par. 3), e da consequente obrigação de "promover a democracia e fortalecer 0 império do direito e o respeito de todos os direitos humanos e liberdades fundamentais internacionalmente reconhecidos, incluindo o direito ao desenvolvimento" (par. 24). Para realizar o direito ao desenvolvimento, foram adoptados oito objectivos internacionais que os Estados-membros das Nações Unidas se comprometeram a concretizar até ao ano 2015. O primeiro é a redução da pobreza extrema e da fome. 0 segundo é a garantia da educação primária para todos.

$\mathrm{O}$ direito ao desenvolvimento tem uma natureza mista, complexa, plural e dialéctica. É um direito dos indivíduos e dos povos (que os Estados representam), mas é, antes de mais, um "direito do homem". É direito a um desenvolvimento global, responsável e solidário com toda a humanidade, no espaço e no tempo, fundado no respeito da dignidade dos seres humanos e na sua participação, para melhorar a sua qualidade de vida, sobretudo dos mais pobres e vulneráveis, por meio da produção sustentável e justa distribuição dos "bens públicos globais" necessários a uma vida digna, saudável, longa e criadora.

As comunidades humanas sempre tiveram necessidade de "bens públicos", isto é, de recursos, bens e serviços que beneficiam cada indivíduo e todos os membros de uma comunidade, mas que ninguém pode ou quer produzir isoladamente. A teoria económica dos "bens públicos" data dos anos de 1950, definidos por oposição aos "bens privados". A noção de "bens públicos globais" só recentemente entrou na cena internacional, com uma publicação do PNUD, em 1999, intitulada G lobal public goods: international cooperation in the $21^{\text {st }}$ Century. São globais porque extravasam o quadro nacional, pela sua natureza ou pelas suas características técnicas. Podem ser repartidos em duas categorias: ético-substanciais e ético-instrumentais. Os primeiros são os valores éticos dos direitos do ser humano; os segundos são outros valores necessários para assegurar os primeiros.

Por consequência, o Direito Internacional do D esenvolvimento deve ser repensado e refundado no direito ao desenvolvimento como direito de aquisição da capacidade de produção e de promoção do consumo equitativo dos "bens públicos globais", para que "o século XXI seja o século do desenvolvimento para todos", como afirma 0 
C onsenso de M onterrey, adoptado pela Conferência internacional sobre o financiamento do desenvolvimento, que se realizou em Monterrey, México, de 18 a 22 de março de 2002.

\section{D ireitos humanos e obrigaçoes dos E stados}

A Declaração sobre o direito e a responsabilidade dos indivíduos, grupos e órgãos da sociedade de promover e proteger os direitos do homem e as liberdades fundamentais universalmente reconhecidos (1998) proclamou a responsabilidade geral de promoção e proteç̧ão dos direitos do ser humano, mas reafirmando que é aos Estados - autores e primeiros destinatários do Direito Internacional - que cabe, em primeiro lugar, "a responsabilidade e o dever de proteger, de promover e de tornar efectivos todos os direitos do homem e todas as liberdades fundamentais", pela adopção de medidas jurídicas, políticas, administrativas, económicas, sociais e outras, como se lê no seu Artigo 2. A responsabilidade dos Estados é a mesma em relação a todos os direitos reconhecidos, que são indivisíveis, porque são interdependentes. Este princípio é uma pedra angular da arquitectura do Direito Internacional dos Direitos do Homem, desde as suas origens. A Conferência mundial sobre os direitos do homem (Viena, 1993) reafirmou-o solenemente. No entanto, as medidas necessárias à realização das diferentes categorias de direitos são tecnicamente variáveis, conforme 0 teor normativo do respectivo objecto.

O Comité dos Direitos Económicos, Sociais e Culturais consagrou a sua O bservação G eral 3 (1990) à interpretação da natureza das obrigações dos Estados-partes no Pacto internacional sobre os direitos económicos, sociais e culturais (1966), segundo o seu Artigo 2.1. Utilizando a terminologia da Comissão do Direito Internacional das Nações Unidas, o Comité começa por afirmar que os Estados têm "obrigações de comportamento e obrigações de resultado". Algumas destas são de "efeito imediato", como a que se refere ao respeito do princípio de não-discriminação (par. 1) e à obrigação de "adoptar medidas" deliberadas e concretas, em vários planos, no sentido da realização de cada um dos direitos enunciados no Pacto (par. 2). Segundo o Comité, cada Estado tem "a obrigação fundamental mínima [minimum core obligation] de assegurar, pelo menos, a satisfação do essencial de cada um dos direitos" (par. 10). No entanto, afirma o Comité na sua Observação Geral 14 ("Direito ao melhor estado de saúde susceptível de ser atingido", Artigo 12 do Pacto): 
Só os Estados podem ser partes no Pacto e, portanto, assumir, no fim de contas, a responsabilidade de respeitá-lo, mas todos os membros da sociedade os particulares (entre os quais, os profissionais da saúde), as famílias, as comunidades locais, as organizações intergovernamentais e não-governamentais, as organizações representativas da sociedade civil e o sector das empresas privadas - têm uma parte de responsabilidade na realização do direito à saúde. O s Estados-partes deverão, pois, criar um ambiente favorável ao exercício dessas responsabilidades. (Par. 42)

"O sector privado como fornecedor de serviços e o seu papel na realização dos direitos da criança" foi tema de um D iscussion D ay (D ia de Debate) do Comité dos D ireitos da Criança (20 de setembro de 2002). Foi a primeira abordagem desta questão por um Comité das Nações Unidas. Eis uma síntese do debate:

- O Direito Internacional dos D ireitos do Homem não vai contra nem a favor da privatização da prestação de serviços públicos, mas atribui aos Estados a responsabilidade primeira pela realização dos direitos que reconhecem, em todas as circunstâncias (descentralização, delegação ou privatização). Como diz o Comité dos Direitos Económicos, sociais e culturais, na sua O bservação G eral 14: "Para determinar que acções ou omissões constituem uma violação do direito (...) importa estabelecer (...) uma distinção entre a incapacidade e a falta de vontade. (...) Convém sublinhar, todavia, que um Estado-parte não pode absolutamente, em caso nenhum, justificar a inexecução das obrigações fundamentais enunciadas (...), que são inderrogáveis" (par. 47). O mais importante, contudo, é que os direitos sejam assegurados, e as parcerias do Estado com actores não-estatais são positivas.

- Em caso de delegação ou privatização da prestação de serviços, deve haver uma avaliação prévia das incidências financeiras e económicas sobre os direitos em causa, envolvendo os sectores governamentais pertinentes e actores civis, designadamente quando se trata de liberalização de serviços no quadro de acordos internacionais. Quando for o caso, 0 Estado deve criar condições favoráveis à prestação dos serviços pelos actores não-estatais, sem deixar de exercer a sua função de regulamentar e controlar, de modo que garanta 0 respeito dos direitos em jogo, designadamente quando os serviços correspondentes são prestados por entidades com fins lucrativos. Outra preocupação do Estado deve ser pre- 
venir a corrupção e impedir a formação de monopólios pelos fornecedores de serviços privados.

- Por seu lado, os actores privados devem adoptar mecanismos de auto-regulação, incluindo um Código de Ética, cujo respeito deve ser controlado por uma instância independente, assim como mecanismos de recurso eficazes. E devem actuar sempre em diálogo com as comunidades.

- Resumindo, os Estados nunca podem privatizar as suas obrigações em matéria de direitos do ser humano, embora os serviços que os satisfazem possam ser prestados por entidades privadas.

J. P. Vallejo, que foi membro do Comité dos Direitos do Homem das Nações Unidas, escreveu: "Um Estado que viola de modo persistente os direitos do homem age contra a comunidade das nações e contra os valores éticos e jurídicos que orientam e condicionam a consciência da humanidade" (Vallejo, 1990, p. 70).

0 brigaçoes dos E stados no domínio do direito à educação

A 18 de fevereiro de 2000, a Organização Internacional para 0 Desenvolvimento da Educação Livre (oID EL) dirigiu ao Comité dos Direitos Económicos, Sociais e Culturais uma tomada de posição, a propósito da sua O bservação G eral 13, relativa ao Artigo 13 do respectivo Pacto. Começando por afirmar que ela "ficará como um marco na história do direito à educação" (par. 3), considera, porém, que "a sua natureza de 'direito-liberdade' não foi suficientemente tomada em conta" (par. 5). Por isso, a O bservação G eral do Comité "não constitui um progresso significativo" na abordagem do direito à educação (par. 6). Se o Estado não subvenciona a liberdade da educação, ela fica esvaziada de sentido. Mais, pode configurar uma forma de discriminação, na medida em que não há liberdade de escolha. Será, pois, "essencial que os órgãos dos direitos do homem adoptem uma abordagem inteiramente nova desta questão da liberdade" (par. 17).

Esta é uma questão tradicionalmente muito sensível, jurídica e politicamente, como documentam os travaux préparatoires das principais disposições internacionais sobre o direito à educação. Vamos considerar três aspectos:

- Há "direito do homem" à educação e liberdade de educação.

- Não há obrigação de financiamento público da educação privada. 
- A satisfação do direito à educação é obrigação indeclinável do Estado.

A educação é um "direito do homem", isto é, cada ser humano tem 0 seu direito à educação, que consiste no direito à liberdade de aprender e de aprender com liberdade. Portanto, no princípio está 0 direito à educação, a menos que se veja nos educandos meros objectos-recipientes da liberdade dos educadores e dos empresários da educação. A liberdade de ensinar é subsidiária do "direito à liberdade de pensamento, de consciência e de religião", reconhecido pelo Artigo 18.1 do Pacto internacional sobre os direitos civis e políticos. O seu parágrafo quarto repete a disposição do Artigo 13.3 do Pacto internacional sobre os direitos económicos, sociais e culturais, que reconhece a liberdade dos pais ou tutores legais de "assegurar a educação religiosa e moral dos filhos de acordo com as suas próprias convicções" e de escolher estabelecimentos de ensino não-públicos para os filhos. Notese, porém, que esta disposição já não se encontra nas disposições relativas ao direito à educação da Convenção sobre os direitos da criança.

A liberdade de criação e direcção de estabelecimentos de ensino é reconhecida no Artigo 13.4 do Pacto internacional sobre os direitos económicos, sociais e culturais, mas "sob reserva de que os princípios enunciados no parágrafo 1 do presente Artigo sejam observados e de que a educação dada nesses estabelecimentos seja conforme às normas mínimas que podem ser prescritas pelo Estado". O s princípios enunciados no parágrafo 1 referem-se à finalidade da educação, em primeiro lugar o "pleno desenvolvimento da personalidade humana". Como observou A.-Ch. Kiss, os valores enunciados naquele parágrafo "poderiam ter sido opostos aos regimes totalitários mais extremistas que nós já conhecemos". Mais, "essas disposições poderiam ser opostas, se necessário, a pais que utilizassem o seu direito de orientar a educação de um filho num sentido muito diferente do das disposições dos instrumentos internacionais, e sobretudo a estabelecimentos de ensino que não respeitassem os objectivos fundamentais assim designados" (Kiss, 1975, p. 438). 0 mesmo se pode dizer, agora, dos valores prescritos no parágrafo primeiro do Artigo 29 da C onvenção sobre os direitos da criança, objecto também de uma cláusula de reserva (segundo parágrafo) análoga à do Artigo 13.4 do Pacto.

A liberdade de criar estabelecimentos de ensino não implica para os Estados a obrigação de financiar escolas privadas, segundo o Comité dos Direitos Económicos, Sociais e Culturais, que disse na sua Observação G eral 13: "Os Estados-partes não têm, de modo ne- 
nhum, a obrigação de financiar estabelecimentos criados em virtude dos parágrafos 3 e 4 do Artigo 13, mas se um Estado decide subvencionar estabelecimentos de ensino privados, deve fazê-lo numa base de não-discriminação". A jurisprudência da C onvenção europeia dos direitos do homem vai no mesmo sentido.

O Comité dos Direitos Económicos, Sociais e Culturais afirma também na sua O bservação Geral 13: "O direito à educação, à semelhança de todos os direitos do homem, impõe três categorias ou níveis de obrigações aos Estados-partes: as obrigações de respeitá-lo, protegê-lo e realizá-lo. Esta última engloba duas obrigações, ao mesmo tempo, a de facilitar o seu exercício e a de assegurá-lo" (par. 46). Como recorda o Comité dos Direitos da Criança, no relatório da sua 22ª sessão (1999), "depois da adopção de um instrumento internacional, dois primeiros desafios se colocam [aos Estados-partes desse instrumento]: é preciso, por um lado, traduzir em obrigações jurídicas nacionais as obrigações jurídicas internacionais contidas no instrumento e, por outro, traduzir as leis nacionais em actos concretos, por meio da sua aplicação quotidiana" (CRC/ C/ 90, par. 269). No que respeita ao Pacto internacional sobre os direitos económicos, sociais e culturais, as obrigações relativas a cada um dos direitos reconhecidos têm uma formulação variável. A plicando os princípios gerais de interpretação apurados em Observações G erais anteriores, o Comité enunciou três tipos de obrigações, na O bservação G eral 13: "O brigações jurídicas gerais", "O brigações jurídicas específicas" e a "O brigação fundamental mínima". Esta consiste em (par. 57):

- "velar para que a educação dispensada seja conforme aos objectivos expostos no parágrafo 1 do Artigo 13";

- "assegurar o acesso, sem discriminação, aos estabelecimentos de ensino e aos programas educativos públicos";

- "assegurar um ensino primário a todos, em conformidade com o parágrafo 2-a) do Artigo 13";

- "adoptar e pôr em prática uma estratégia nacional em matéria de educação que englobe 0 ensino secundário e superior e a educação de base";

- "garantir a livre escolha da educação, sem ingerência do Estado ou de terceiros, sob reserva de que seja conforme às 'normas mínimas em matéria de educação'” (Artigo 13, par. 3 e 4).

Q uanto às obrigações internacionais, o Comité observa que, "para os autores do Pacto, a expressão 'no máximo dos seus recursos 
disponíveis' visava, ao mesmo tempo, aos recursos próprios de um Estado e aos da Comunidade Internacional, disponíveis mediante a assistência e a cooperação internacionais" (par. 13).

0 Comité recorda, ainda: "O direito à educação pode ser violado por uma acção directa do Estado-parte (acção) ou pela nãoadopção de medidas requeridas pelo Pacto (omissão)" (par. 58). E evoca 0 Artigo 22 do Pacto para chamar também a atenção para 0 papel dos vários organismos das Nações Unidas, nomeadamente 0 BM e o FMI, concluindo: "A adopção pelas instituições especializadas, programas e órgãos das Nações Unidas de um procedimento fundado nos direitos do homem facilitará grandemente a realização do direito à educação" (par. 60).

A especificidade da educação e a responsabilidade pública pelo direito à educação são objecto de um vasto consenso, como testemunham os documentos que vão ser citados:

- Nos termos do Acordo Geral sobre o Comércio dos Serviços (GATS), Artigo primeiro (Alcance e definição):

3. Para os fins do presente acordo:

(...)

b) os "serviços" compreendem todos os serviços de todos os sectores, com excepção dos serviços fornecidos no exercício do poder governamental;

c) entende-se como "serviço fornecido no exercício do poder governamental" todo o serviço que não é fornecido nem numa base comercial nem em concorrência com um ou vários fornecedores de serviços.

Avançando nesta nova direcção, a omc criou um Grupo de Trabalho, em 1998, para estudar a liberalização dos serviços da educação. A 23 de setembro desse mesmo ano, foi divulgada internamente uma extensa "Nota de informação do Secretariado" da omc (S/ C/ W/ 49), com vista a "fornecer indicações de base para as discussões sectoriais a que deve proceder o Conselho" [do comércio dos serviços] e "estimular a discussão das questões em jogo pelos Estados-membros". Justifica-se transcrever, aqui, algumas passagens da Nota do Secretariado, relativas ao enquadramento da educação no GATS:

3. O s serviços de educação são correntemente definidos pela sua classificação em quatro categorias: os serviços de ensino 
primário, secundário, superior (do terceiro grau) e de ensino destinado aos adultos. (...)

6. O papel crucial que a educação desempenha para favorecer o crescimento económico e o desenvolvimento pessoal e social e para reduzir as desigualdades não sofre contestação. (...)

9. A educação é geralmente considerada um artigo destinado ao "consumo público", que é muitas vezes fornecido gratuitamente ou a preços muito abaixo dos custos de produção. As despesas públicas têm sido, pois, a fonte principal de financiamento da educação na maior parte dos países. (...)

10. A educação é também um artigo destinado ao "consumo privado", cujo preço é determinado livremente pelos estabelecimentos que o fornecem. (...)

12. Dada a sua importância para o desenvolvimento humano e social, os países do mundo inteiro tendem a considerar a educação até um certo nível - geralmente 0 ensino primário e secundário - como um direito fundamental. Em geral, é assegurada gratuitamente pelos poderes públicos e, na maior parte dos países, a escolarização é obrigatória. Paralelamente, há um certo grau de participação do sector privado no fornecimento da educação, variável segundo os países. Todavia, os acordos institucionais em que se funda esta participação podem ser muito diversos, de modo que a distinção entre o público e o privado nem sempre é nítida. Assim, os estabelecimentos de ensino privado podem ser fortemente subvencionados e fornecer serviços análogos aos que são fornecidos pelo sector público, ou pouco diferentes. Pelo contrário, acontece que alguns estabelecimentos privados oferecem serviços nas condições do mercado (escolas de línguas, por exemplo).

13. A educação de base assegurada pelo governo pode ser incluída, segundo a terminologia do GATS, nos serviços fornecidos no exercício do poder governamental (que não são fornecidos nem numa base comercial nem em concorrência). [Nota: "A educação de base corresponde ao ensino primário e secundário."] (...)

- O Relatório mundial sobre o desenvolvimento humano - 2001 do PNUD exprime também este ponto de vista: “O Estado 
deve conservar a responsabilidade da escolaridade primária universal, da educação secundária e de uma parte do ensino superior" (Capítulo 4).

- O Comité dos Direitos Económicos, Sociais e Culturais, na sua Observação Geral 13, constata: "A obrigação de prosseguir activamente ' 0 desenvolvimento de uma rede escolar em todos os escalões' reforça a ideia de que os Estados-partes têm a responsabilidade principal de assegurar directamente o exercício do direito à educação, na maior parte dos casos" (E/ C.12/ 1999/ 10, par. 53).

- A relatora especial sobre o direito à educação escreveu nos seus relatórios para o Comité dos Direitos do Homem (Nações Unidas): ${ }^{4}$

Esta afirmação da prioridade do ensino público sobre as escolas privadas vai para além da questão do financiamento: 0 papel do ensino na socialização da criança privilegia a integração relativamente à segregação. Segundo a fórmula bem conhecida do Supremo Tribunal dos Estados-Unidos, "estabelecimentos de ensino separados são, por essência, desiguais”. (E/ CN.4/ 2000/ 6, par. 36)

A educação continua a ser considerada uma responsabilidade das autoridades e como um serviço público pela esmagadora maioria dos governos do planeta. (...) Além disso, as propostas que vão no sentido de uma maior liberalização limitam-se geralmente ao ensino pós-obrigatónio e acentuam o facto de o ensino dispensado pelo sector privado dever completar, e não substituir, o ensino público. (...)

Q uando se comercializa, a educação rege-se pelo Direito Comercial e, porvezes, chama-se-lhe "direito de propriedade". (...) O s direitos humanos pertencem intrinsecamente aos seres humanos e regem-se pelo Direito Público, não pelo privado. (...) Tanto no plano interno como no nível internacional, a preocupação pelo futuro da educação como serviço público gratuito acentuou a necessidade de reafirmar e reforçar a educação como direito humano. (E/ CN.4/ 2002/ 60, par. 20, 21, 36)

- O Relatório Delors considera que "a educação é um bem colectivo que deve ser acessível a todos" e "não pode ser objecto de uma simples regulação pelo mercado". Cabe à política da educação "iluminar o futuro por uma visão a longo prazo" e realizar "um duplo objectivo: a qualidade do ensino e a equidade" (D elors et al., 1996, p. 28, 182, 175, 19, 20).

- Na sua E stratégia a médio prazo - 2002-2007, a UNESCO, considerando, designadamente, que "a exploração comercial 
crescente de muitos domínios outrora considerados bens públicos, tais como o ensino, a cultura e a informação, põe em perigo os elementos da comunidade mundial mais fracos e privados de poder económico, mas nem por isso menos importantes que os outros" (par. 25), propõe-se "elaborar princípios e normas, fundados em valores comuns, para responder aos novos desafios nos domínios da educação, da ciência, da cultura e da comunicação e para preservar e consolidar 0 'bem público comum'” (par. 27a), guiada "por três princípios essenciais e indissociáveis: universalidade, diversidade e dignidade" (par. 28). No que respeita ao direito à educação, em particular, pretende-se alcançar estes objectivos, nomeadamente (par. 63):

- Relançamento, no plano internacional, do debate público sobre 0 direito à educação.

- Elaboração de directivas e de normas comuns, nomeadamente de um projecto de instrumento normativo unificando os diversos aspectos do direito à educação.

Por consequência, a responsabilidade jurídica e política do Estado, no domínio do direito à educação, é clara e indiscutível. Há um mercado da educação, mas o direito à educação não está no mercado.

D epois do direito de viver - o primeiro dos direitos de cada ser humano, com os conexos direitos básicos à alimentação, à habitação e a cuidados de saúde elementares - , todos os direitos se resumem num meta-direito ao desenvolvimento como direito a uma vida com o maior nível de dignidade humana possível. É, portanto, direito a um processo de desenvolvimento que respeite e favoreça a realização de todos os direitos. Um processo em que, como escreveu Amartya Sen, "a liberdade é não só o objectivo primeiro do desenvolvimento, mas também o seu meio principal”. Assim concebido, o direito ao desenvolvimento é, na opinião de Moahmmed Bedjaoui, "o alfa e 0 omega dos direitos humanos, o primeiro e o último direito humano, o princípio e o fim, o meio e o objectivo dos direitos humanos, numa palavra, é o direito nuclear do qual derivam todos os outros (...) o corolário do direito à vida". Um direito, "pela sua natureza, tão incontrovertível, que deveria ser reconhecido como parte do jus cogens" (apud Steiner \& Alston, 2000, p. 1.317, 1.321... 1.322). Mas se o sentido do direito ao desenvolvimento deve ser o desenvolvimento da pessoa humana, a chave do desenvolvimento, na sua di- 
mensão individual e colectiva, cultural, política, económica, ecológica, está no direito à educação. É o mais fundamental dos direitos para uma vida humana, tanto para as gerações presentes como para as gerações futuras. Por isso, tem razão o director geral da unEsco para escrever: "Subestima-se, com demasiada frequência, a importância que tem a educação para enfrentar a globalização" (Matsuura, 2000).

\section{Algumas conclusões}

A formação do Direito Internacional da Educação é um capítulo novo na História da Educação. As suas normas constituem a fonte mais elevada na hierarquia da normatividade contemporânea da educação, devendo ser 0 vértice da legitimidade, coerência e unidade da pirâmide normativa da educação dos Estados que a ele se obrigam. Por isso, deverá ser reconhecido e estudado como uma nova "ciência da educação", uma disciplina-interface entre a história e a teoria da educação. Hoje, os educadores profissionais precisam de uma cultura pedagógica com dimensão jurídica, para recriar a sua identidade e distinção como profissionais do direito à educação. Mas também os pais precisam de aprender a amar e a educar os filhos, aprender a exercer a autoridade inerente à sua responsabilidade e necessária à sua respeitabilidade. A educação não sairá da sua pré-história enquanto a educação dos filhos não começar pela educação dos pais.

Na verdade, educação e "direito à educação" não são a mesma coisa. A educação é necessária, mas nem toda a educação é legítima. Educação houve sempre, direito à educação, como direito universal do ser humano, só há depois da D eclaração universal dos direitos do homem. A educação tradicional é um "direito de educação", isto é, um direito do homem sobre 0 homem. 0 "direito à educação" é um direito do homem, isto é, tem uma significação ética. A ética do direito à educação é uma ética do interesse superior do educando, que não pode ser tratado e instrumentalizado como "objecto" de educação, mas deve ser considerado e respeitado sempre como "sujeito" do seu direito à educação. 0 direito à educação não é um direito dos pais sobre os filhos, nem do Estado sobre os cidadãos. É um direito dos filhos e dos cidadãos às responsabilidades dos pais e do Estado para com o seu direito à educação.

Direito à educação não é direito apenas à disponibilidade e acessibilidade de uma educação qualquer, avaliada por indicadores meramente utilitários e quantitativos. E, por definição, direito a uma bem determinada qualidade de educação, a uma educação com qua- 
lidade ético-jurídica de direito do ser humano, isto é, cujas condições materiais, institucionais e pessoais respeitem todo o conteúdo normativo, devidamente interpretado, do direito à educação. Por outras palavras, direito à educação é direito a uma $\mathrm{E}$ ducação de D ireito, ou seja, a uma educação conforme ao Direito Internacional da Educação, traduzido em Princípios de D ireito Pedagógico, de que derivam D ireitos do E ducando, que reclamam uma Política do D ireito à E ducação e uma Pedagogia do D ireito à E ducação.

Por consequência, o direito à educação é um paradigma novo. 0 direito de educação tradicional é um paradigma de subdesenvolvimento ético, psicológico e político. O novo direito à educação tem uma significação revolucionária que pode ser resumida nestes termos metafóricos: a educação já não está centrada na terra dos adultos, nem no sol da infância, mas projectada no universo dos direitos do ser humano, onde não há maiores e menores, pais e filhos, professores e alunos, mas sujeitos iguais em dignidade e direitos. Sendo assim, a razão pedagógica já não é a razão biológica da Família, nem a razão política do Estado, mas a razão ética do Educando, que limita tanto a omnipotência estatal como 0 arbítrio parental.

Em suma, o paradigma do direito à educação é uma nova racionalidade ético-jurídica para a ruptura político-pedagógica do círculo vicioso de auto-reprodução histórica e psicológica dos males seculares da educação.

Recebido em julho de 2003 e aprovado em agosto de 2003.

\section{Notas}

1. A Carta Internacional dos Direitos do Homem, elaborada no quadro universal das Nações Unidas, é formada pela D eclaração universal dos direitos do homem, proclamada em 1948, e pelos dois Pactos internacionais adoptados em 1966, com seus protocolos: o Pacto internacional sobre os direitos civis e políticos e o Pacto internacional sobre os direitos económicos, sociais e culturais.

2. Uma "Observação Geral" ou "Recomendação Geral" é um texto elaborado por um comité das Nações Unidas, estabelecendo princípios de interpretação e aplicação dos direitos do ser humano reconhecidos no tratado cujo respeito lhe compete controlar.

3. Le monde, "Manière de voir 69 - L'Amérique Latine en effervescence", juin-juillet 2003.

4. A nomeação de um(a) "relator(a) especial" é um dos mecanismos extra-convencionais (ex tra conventional mechanisms ou procédures spéciales, isto é, não fundados num tratado) a que recorre o Comité dos Direitos do Homem para dar mais visibilidade a um direito e reforçar a sua protecção. 
ARANG UREN, J.L.L. É tica y política. Madrid: Biblioteca Nueva, 1996. (2. ed. 1999).

BACHELARD, G. L a poétique de la rêverie. Paris: Puf, 1960.

BADINTER, R. Rapport final. In: UN IV E RSA LITÉ des droits de l'homme dans un monde pluraliste: actes du colloque organisé par le Conseil de l'Europe en collaboration avec l'Institut International des D roits de l'Homme, 17-19 avril 1989, Strasbourg. Strasbourg: N. P. Engel, 1990. p. 181-188.

DELORS, J. et al. L'éducation: un trésor est caché dedans; rapport à l'unesco de la Commission Internationale sur l'Éducation pour le Vingt et Unième Siècle. Paris: O dile Jacob, 1996.

FOX, J. Chomsky and globalisation. Cambridge: Icon, 2001 (2002).

KISS, A.-C. La protection du droit à l'éducation dans le cadre de la protection internationale des droits de l'homme depuis 1948. In: RECUEIL de la Société Jean Bodin pour l'histoire comparative des institutions, v.39 : L'enfant. 5e. partie: Le droit à l'éducation. Bruxelles: Librairie Encyclopédique, 1975. p. 417-439.

MATSUURA, K. ¿Está creando la globalización de la economía valores para una nueva civilización? Perspectivas, unesco, v. 30, n. 4, dic. 2000.

MÜNSTER, A. L e principe dialogique: de la réflexion monologique vers la pro-flexion intersubjective ;essais sur M. Buber, E. Lévinas, F. Rosenzweig, G. Scholem et E. Bloch. Paris: Kimé, 1997.

PERSCHEL, W. Recht auf Bildung. In: Lenzen, D. (Ed.) E nzyklopädie E rziehungswissenschaft: Handbuch und Lexikon der Erziehung in 11 Bänden und einem Registerband. Stuttgart: Klettt-Cotta, 1984. v. 5 p. $549-553$.

PROGRAMME DES NATIONS UNIES POUR LE DÉVELOPPEMENT. Rapport mondial sur le développement humain 2000 : mettre les nouvelles technologies au service du développement humain. Paris; Bruxelles: De Boeck \& Larcier, 2001. 
PRZETACZNIK, F. The philosophical concept of the right to education as a basic human right. Revue de D roit International de Sciences D iplomatiques et Politiques, Genève, v. 63, p. 257-288, 1985.

STEINER, H.J.; ALSTON, P. International human rights in context: law, politics, morals. 2. ed. New York: Oxford University, 2000.

SUPIO T, A. Pourquoi un droit du travail?. D roit social, n. 6, p. 485492, juin 1990.

VALLEJO, J.P. Force et développement des droits de l'homme. Bulletin des D roits de l'H omme, v. 89/1, p. 70-76, 1990.

VAN BUEREN, G. The international law on the rights of the child. D ordrecht: Martinus Nijhoff, 1995. (International Studies in Human Rights, v. 35).

VERD O ODT, A. N aissance et signification de la D éclaration U niverselle des D roits de l'H omme. Louvain: Nauwelaerts, 1964. 